\title{
CURSO DE GRADUAÇÃO LICENCIATURA EM PEDAGOGIA NA MODALIDADE A DISTÂNCIA (PEAD): CONCEPÇÃO, REALIZAÇÃO E REFLEXÕES
}

\author{
Rosane Aragón, FACED - UFRGS \\ rosane.aragon@ufrgs.br \\ Crediné Silva de Menezes, FACED - UFRGS \\ credine@gmail.com \\ Silvestre Novak, SEAD - UFRGS \\ silvestre.novak@ufrgs.br
}

Resumo: o presente artigo tem como objetivo apresentar o Curso de Graduação em Pedagogia - Licenciatura na Modalidade a Distância (PEAD), resgatando na sua primeira parte as motivações iniciais e o projeto, destacando a proposta pedagógica, seus princípios e componentes. A segunda parte do artigo focaliza os papéis desempenhados pelos formadores e tutores, as etapas e os desafios que envolveram a dinâmica da realização do PEAD. Na terceira parte, trazemos algumas considerações sobre os resultados do curso, destacando os seus impactos e as avaliações realizadas pelas professoras-alunas. Essas avaliações enfatizam às características do curso que favoreceram as aprendizagens, bem como as principais contribuições do PEAD para as mudanças percebidas pelas professorasalunas na vida profissional, pessoal e de estudante.

Palavras-chave: Educação a Distância, Formação de professores em serviço, Pedagogia.

\section{A LICENCIATURE COURSE IN PEDAGOGY IN DISTANCE MODALITY: CONCEPTION, REALIZATION AND REFLECTIONS}

\begin{abstract}
This article presents an undergraduate course to train teachers for initials grades of elementary school (PEAD), a distance education project. The first part, presents the initial motivations and course design, highlighting the pedagogical proposal, its principles and components. The second part of the article focuses on the roles of teacher and tutors, the steps and challenges surrounding the implementation of the course. In the third part, we present some considerations about the results of the course, highlighting their impacts and assessments by students. These assessments emphasize the characteristics of the course that positively influenced the learning, as well as its the main contributions for the changes perceived by students with regard to aspects of personal, professional and academic life.
\end{abstract}

Keywords: Distance Education, in-service teacher training, Pedagogy. 


\section{Parte I - A Preparação}

\section{A decisão}

O desafio chegou mediante a Chamada Pública 01/2004 MEC/SEED (Pró-Licenciatura, fase I), trazendo a oportunidade de oferecer, na modalidade a distância, cursos de licenciatura. A decisão de propor o primeiro curso de licenciatura a distância da UFRGS foi resultado do entusiasmo e comprometimento da direção e de docentes da Faculdade de Educação (FACED). Partindo de experiências e pesquisas já realizadas na FACED, optamos por elaborar um curso dentro de um modelo diferenciado que pudesse trazer inovações metodológicas e tecnológicas na formação de professores.

Surgia assim, o Curso de Graduação em Pedagogia - Licenciatura na Modalidade a Distância (PEAD), em consórcio com a Universidade Federal de Santa Catarina (UFSC), através de seu Centro de Educação, que colaborou na produção de material didático previsto para o Curso e na preparação da equipe docente. ${ }^{1}$

Para a realização do PEAD foram firmados convênios com as prefeituras de Alvorada, Gravataí, Sapiranga, São Leopoldo e Três Cachoeiras, municípios do Estado do Rio Grande do Sul, que disponibilizaram os polos de apoio para a realização de atividades presenciais. O curso ofereceu 400 vagas para graduar professores em exercício nos Anos Iniciais do Ensino Fundamental, na Educação Infantil e na Gestão Escolar de escolas públicas estaduais e municipais do Estado do Rio Grande do Sul.

\section{A proposta pedagógica: Educação em serviço e sem distâncias}

Para elaboração do projeto pedagógico, tomou-se como ponto de partida o Projeto Institucional da UFRGS (1996), que enfatiza a produção de saberes e a inovação. A decisão de oferecer o curso a professores em serviço foi uma resposta da Faculdade de Educação (FACED/UFRGS) à demanda de titulação em nível superior de professores que não teriam condições de frequentar um curso presencial, seja pelos impedimentos de deslocamento, seja pela dificuldade em afastar-se das atividades profissionais.

Em consonância com as Diretrizes Curriculares Nacionais para o Curso de Graduação em Pedagogia, licenciatura (CNE 2006), o PEAD estabeleceu um currículo com o objetivo de habilitar as professoras-alunas ${ }^{2}$, simultaneamente, nas seguintes áreas: Docência em Educação Infantil e Anos iniciais do Ensino Fundamental; Docência em Educação de Jovens e Adultos (EJA); Gestão Escolar; Docência nas matérias pedagógicas na Modalidade Normal e Docência em Cursos de Educação Profissional para a área de Serviços e Apoio Escolar.

Considerando as especificidades dessa população, a proposta de formação de professores no PEAD apresentou características próprias, diferenciadas de outros cursos regulares de Pedagogia, embora “[...] com eles mantendo as interfaces determinadas pela própria natureza dos conhecimentos envolvidos na formação humana em geral” (BRASIL, 1999). A proposta do PEAD considera que a formação de professores é práxis social, resultante das interações que medeiam a construção do conhecimento no sentido de permitir aos sujeitos envolvidos neste processo refletirem sobre a própria cultura e os contextos sociais a que pertencem. Para tal, a formação parte da experiência dos professores-alunos nos seus espaços de docência, construída nas suas reflexões e práticas, bem como nas suas 
$\Gamma$

condições de vida e trabalho, visando articular a prática e a teoria. (BORDAS, NEVADO E CARVALHO, 2004)

Na perspectiva de atender à especificidade de um processo que é, ao mesmo tempo, de formação inicial e continuada de professores, o Projeto Político Pedagógico do Curso (BORDAS, CARVALHO E NEVADO 2005; NEVADO, 2006) organizou-se em função de três pressupostos básicos:

- autonomia relativa da organização curricular, considerando as características e experiências específicas dos sujeitos aprendizes;

- articulação dos componentes curriculares entre si, nas distintas etapas e ao longo do curso;

- relação entre Práticas Pedagógicas e Pesquisa como elemento articulador dos demais componentes curriculares, constituída como estratégia básica do processo de formação de professores.

A partir da criação de um currículo diferenciado, articulado em eixos e interdisciplinas, da aplicação de metodologias interativas e do uso intensivo das tecnologias digitais, o PEAD propõe superar a dicotomia apresentada pelos modelos convencionais de cursos de formação de professores, que teorizam sobre as transformações nas práticas educativas, sem que essas transformações sejam vivenciadas no próprio ambiente de formação.

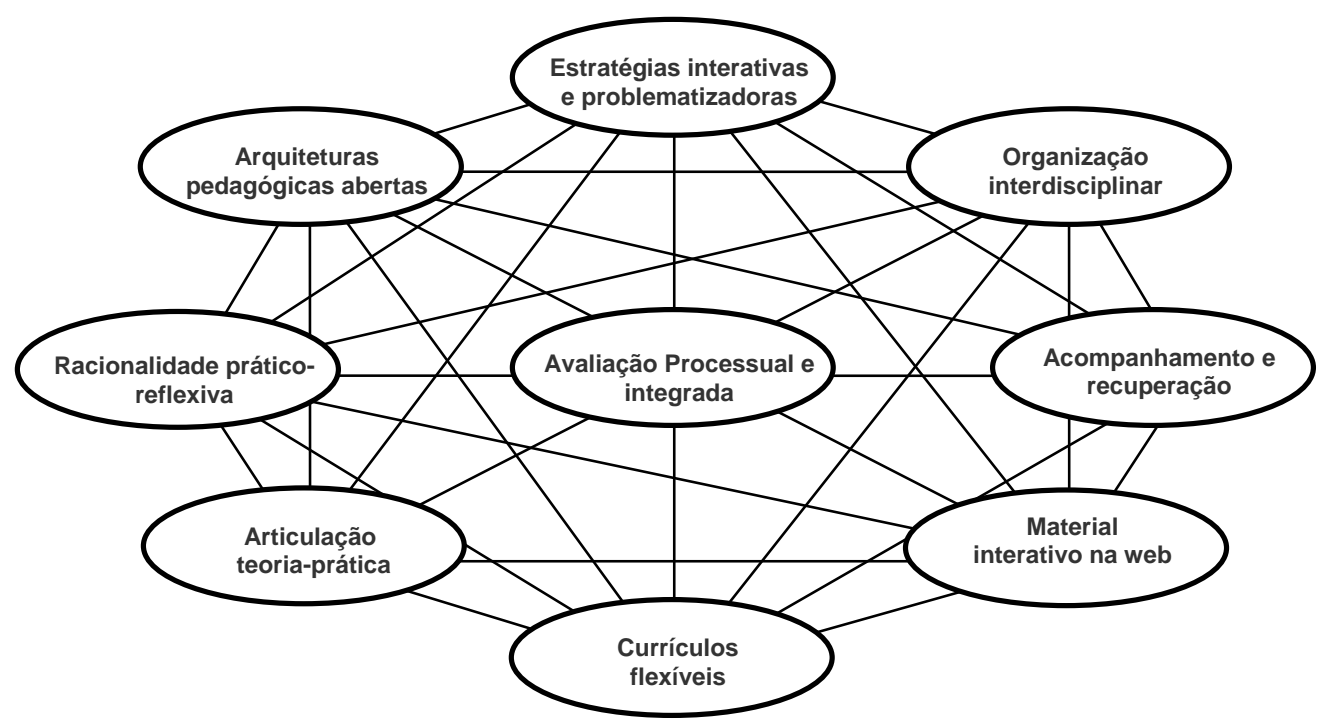

Figura 1 : Projeto Pedagógico do PEAD (Adaptado de Nevado, Carvalho e Menezes, 2009)

A proposta pedagógica enfatiza a importância da "presença” nos processos de formação a distância, destacando a interação como a forma privilegiada de "encurtar 


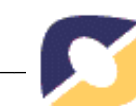

distâncias” e evitar a sensação de isolamento que se tem mostrado um dos principais fatores da evasão.

Os principais componentes da proposta pedagógica estão representados na Figura 1 e comentados a seguir:

Arquiteturas pedagógicas abertas: arquiteturas pedagógicas são definidas como "suportes estruturantes" para a aprendizagem. Conforme Carvalho, Nevado e Menezes (2007), elas são configuradas pela confluência de diferentes componentes, enfatizando-se: a abordagem pedagógica, software, internet, educação a distância, concepção de tempo e espaço. As arquiteturas pressupõem pedagogias abertas, capazes de suportar situações de aprendizagem interativas, mais flexíveis, e adaptáveis a diferentes contextos, além de uma ampliação dos espaços e tempos da aprendizagem.

Articulação entre teoria e prática: o modelo de formação propõe a prática das teorizações sobre inovações, buscando avaliar as suas possibilidades para provocar mudanças substanciais nas conceituações e práticas educacionais dos professores que vivenciam essa formação. Para tal, o curso parte da experiência dos professores em serviço, bem como das suas condições de vida e trabalho ao propor articular essas experiências a um aprofundamento teórico que permita a qualificação das práticas pedagógicas.

Organização interdisciplinar: O PEAD propõe um currículo com características interdisciplinares, articulado na perspectiva de rompimento dos limites rígidos das disciplinas, porém sem prescindir da especificidade disciplinar, ampliada pelo diálogo que é necessário entre as áreas para formar qualquer conhecimento. A proposta se viabiliza na medida da superação, por parte dos docentes e tutores, da ideia de domínio sobre seus respectivos campos de saber e sobre seus espaços próprios de atuação na perspectiva de cooperação. (BORDAS, NEVADO E CARVALHO, 2004)

O curso foi concebido em nove eixos temáticos (215 créditos- 3225h), a serem desenvolvidos em nove semestres acadêmicos. Cada um dos eixos engloba um grande tema norteador, no qual os conteúdos e as atividades se desdobram em interdisciplinas e enfoques temáticos. Como parte da estratégia em prol da integração das interdisciplinas, foi proposto o Seminário Integrador (SI). O SI, pelo seu caráter de articulação, apresenta flexibilidade programática. Em uma de suas frentes de atuação apoia o desenvolvimento da iniciação à pesquisa, de "ferramentas intelectuais" e de metodologias para apoiar e integrar o trabalho pedagógico em cada um dos eixos. Além disso, o Seminário tem como responsabilidade a orientação do desenvolvimento do portfólio educacional, realizado em todos os semestres e definido como uma alternativa de sistematização no acompanhamento e na avaliação da aprendizagem.

Materiais pedagógicos interativos na web: Os materiais são concebidos a partir de Arquiteturas Pedagógicas Abertas que incentivam a pesquisa e a interação. Como se trata de um curso que busca a construção de conhecimento, a flexibilidade de propostas e materiais mostra-se fundamental para que seja possível aproximá-las das necessidades 
$\Gamma$

cognitivas dos alunos. Nessa ideia, os materiais digitais substituem os fascículos impressos, permitindo a atualização constante e a sua reorganização em curto prazo.

Estratégias interativas e problematizadoras:. Os docentes e tutores atuam como "possibilitadores" da aprendizagem e provocadores de transformações cognitivas ao usar, para tal, duas estratégias complementares e interdependentes: (a) estratégias de problematização, com as quais a equipe docente busca provocar reflexões e críticas acerca das concepções/certezas das professoras-alunas, sejam essas relativas aos conceitos teóricos, às práticas, às crenças, valores ou outros, podendo ser consideradas como um elemento ativador do processo de desenvolvimento (b) estratégias de apoio a reconstrução da equipe docente onde a ação se dá no sentido de apoiar a superação dos conflitos e desequilíbrios, alargando o campo de novas possibilidades.

Aprendizagem em rede: As interações nos ambientes virtuais fortalecem a educação continuada a distância baseada nas trocas entre os alunos, docentes e tutores. Considerando que um dos grandes fatores de permanência e produtividade em cursos a distância é o sentimento de pertencimento ao grupo, o PEAD incentiva os alunos a criarem redes de integração e comprometimento. Essas interações, conforme Costa, Fagundes e Nevado (1998), caracterizam uma comunidade virtual, pois não se confundem com a simples construção de espaços físicos na rede, mas implicam em ligações entre pessoas que partilham ideias, atividades ou tarefas que podem auxiliar a qualificar a formação.

Avaliação da aprendizagem: no PEAD, a avaliação parte de uma concepção de aprendizagem como um processo contínuo que tem como fonte a ação e a reflexão do sujeito sobre o seu ambiente (físico, social, simbólico), permitindo que o sujeito compreenda o mundo e a si mesmo (metacognição) numa construção dialética. Como consequência dessa perspectiva de aprendizagem, a avaliação no curso desloca o seu foco: (i) das performances e produtos para os processos construtivos de novos instrumentos cognitivos e (ii) das observações e "julgamentos" externos, que comparam o sujeito a algum ideal que ele deva alcançar, para as análises e autoanálises do desenvolvimento do próprio sujeito (metarreflexões).

\section{Parte II - A Realização}

\section{A produção dos materiais}

Após a aprovação do projeto pedagógico pela SEED/MEC, em junho de 2005, iniciamos a formação interna para o uso das tecnologias (TDIC) e a criação dos materiais na web, buscando explorar os ambientes e materiais virtuais. A opção pela produção de materiais na web foi motivada pela proposta do curso que necessitava, para a sua concretização, de suportes interativos para a formação de redes de aprendizagem.

Para o planejamento e produção dos materiais interativos na web foram formadas equipes por eixos do curso. Ainda que a produção dos materiais tenha ocorrido antes do início do curso, a cada semestre estes foram reconstruídos pelas equipes formadoras, V. $11 \mathrm{~N}^{\circ}$ 2, novembro, 2013 PEAD 
$\Gamma$

responsáveis por cada uma das interdisciplinas, Em cada um dos semestres (eixos) os formadores realizavam reuniões de trabalho com os tutores do curso para experimentação e avaliação dos materiais. O feedback dos tutores servia como base para a realização de ajustes das propostas de trabalho, considerando a sua adequação quanto às arquiteturas propostas, ao tempo previsto para a realização etc.

Além disso, durante a realização das interdiciplinas, os formadores puderam realizar adequações nos materiais e propostas a partir das interações com as professoras-alunas, flexibilizando as propostas conforme os contextos da sua aplicação.

Como materiais impressos foram produzidos exclusivamente, guias de orientação, direcionados a alunos, professores (formadores) e tutores.

\section{As professoras- alunas}

O ingresso ocorreu mediante processo seletivo especial, realizado nos cinco polos do curso: Alvorada, Gravataí, Sapiranga, São Leopoldo e Três Cachoeiras, todas situadas no Estado do Rio Grande do Sul. O PEAD realizou um primeiro processo seletivo em agosto de 2006/2, com o ingresso de 285 alunos e em 2007 realizou-se um novo ingresso complementando as 400 vagas disponíveis (80 vagas em cada polo).

A maioria dos alunos do curso foi composta de alunas-professoras (98\% $\mathrm{N}=400$ ) que, ao ingressarem no curso, apresentaram, em média, 36 anos de idade . A carga horária semanal de trabalho média era de 35 horas, sendo que, aproximadamente, 5\% das alunasprofessoras trabalhavam 60 horas semanais e o tempo de experiência no magistério distribuiu-se, majoritariamente, entre 5 e 15 anos. No início do curso, cerca de 30\% das alunas-professoras não dispunham de computador e $40 \%$ não dispunham de acesso à internet em suas residências. Destaca-se, ainda, que a maioria das alunas-professoras atuava nos anos iniciais do Ensino Fundamental. Menos de um terço das alunas atuava na Educação Infantil, na gestão da escola, na Educação de Jovens e Adultos ou em classes e escolas que atendem alunos com necessidades educacionais especiais. Essas características da população-alvo exigiram esforços da equipe docente no sentido de compreender a situação, as necessidades e as demandas dessas professoras-alunas. Conforme Nevado, Carvalho e Menezes (2009) esses fatores desafiaram a proposição de um currículo que articulasse a experiência em sala de aula com os aportes teóricos, materializando-se em práticas pedagógicas inovadoras, renovadas ou ressignificadas pelas professoras-alunas.

\section{Formação e papéis dos docentes formadores}

O corpo docente do PEAD foi formado por uma grande maioria de professores doutores ou pós-doutores (78,4\% dos 74 docentes do Curso) e de mestres (21,6\% do total de docentes). Desses docentes, 30\% já apresentavam experiência em formação de professores em ambientes digitais. Os professores assumiram a responsabilidade pelas propostas de estudos teórico-práticos, pela definição dos aspectos a serem considerados na análise das atividades realizadas pelos alunos, pela avaliação e pela realização de parte do feedback, função esta que foi compartilhada com os tutores. 


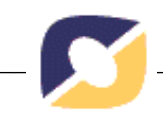

A formação específica para a docência a distância desenvolveu-se de forma continuada, conforme as necessidades das equipes, considerando a experiência anterior em EAD e no uso de tecnologias. Nessa formação foi estimulada a criação de novas arquiteturas pedagógicas sintonizadas com os recursos disponíveis, com o contexto sociocultural, com o desenvolvimento e com o interesse dos alunos. Os docentes foram, também, responsáveis pela orientação dos tutores quanto às sistemáticas de feedback, aos atendimentos online e aos registros específicos de acompanhamento de atividades.

Os docentes responsáveis pelo Seminário Integrador, que exerciam também a função de Coordenadores de Polo3 foram responsáveis pelas equipes de trabalho (docentes e tutores), visando um desenvolvimento integrado dos eixos (semestres) do curso nos cinco polos. Bicca (2012) investigou como a interdisciplinaridade se desenvolveu nas relações estabelecidas entre disciplinas e os professores formadores no PEAD, constatando que na medida em que os professores trabalhavam em equipes, de forma cooperativa, as concepções e as práticas interdisciplinaridade foram se reconstruindo e se traduzindo em ações, como o que é observado nas propostas de avaliação integrada.

Para fortalecer essa integração e favorecer o estabelecimento de vínculos, buscamos manter a equipe do Seminário Integrador durante os nove eixos do curso.

\section{Formação e papéis dos tutores}

Os Tutores a Distância eram, na sua maioria, alunos de mestrado ou doutorado com formação específica na área da Educação. Sua função principal consistiu em realizar intervenções diretas (feedback) sobre as atividades realizadas e registradas nos ambientes virtuais; acompanhar e orientar cada aluno nas atividades propostas nas Interdisciplinas, incentivar a participação e a reflexão.

Os Tutores Presenciais eram professores das redes públicas de ensino dos municípios-polos, graduados em Pedagogia ou áreas afins e, na sua maioria, com especialização em Educação. A função geral desses tutores era proporcionar acompanhamento e orientação personalizada em atividades individuais e de grupo; incentivar a participação na comunidade de aprendizagem e estabelecer vínculos com cada estudante.

Os tutores realizaram, antes do início do curso (em 2005), uma formação de 180 horas e, em paralelo ao trabalho no PEAD, cursaram a especialização "Tutoria em Educação a Distância” (ESPEAD) com 360 horas, desenvolvido nas modalidades presencial e a distância.

Considerando-se que a tutoria é uma função que assume diferentes formas num curso que adota arquiteturas pedagógicas flexíveis, os tutores do PEAD vivenciaram na sua formação uma prática semelhante àquela vivenciada pelos alunos do curso. A capacitação continuada foi integrada às reuniões de trabalho específicas de cada interdisciplina e com as equipes que atuaram em cada polo. Ziede (2008) analisou o processo de construção da função de tutoria no PEAD mostrando que os tutores, de forma gradual, foram tomando consciência do seu papel, o que envolveu a compreensão da proposta do curso, o uso das estratégias de mediação e a apropriação tecnológica. Dos Santos (2012) focaliza as relações estabelecidas entre os tutores e as professoras-alunas do PEAD a partir da perspectiva do diálogo a partir do cuidado de si, apontando que é necessário aos tutores uma compreensão 


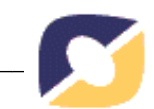

da potencialidade do diálogo para que esses possam criar formas de interação que favoreçam o conhecimento.

A equipe de tutoria manteve-se, em sua maior parte, desde os primeiros semestres do curso, em um mesmo polo. Em virtude disso, os tutores puderam conhecer e acompanhar de forma individualizada os alunos com quem trabalharam. Este acompanhamento mostrou-se fundamental para apoiar o trabalho de prevenção da evasão, para enriquecer o processo de aprendizagem e de avaliação, bem como para planejar os momentos de recuperação e o redirecionamento das atividades.

\section{Desenvolvimento do curso}

O PEAD teve início, em agosto de 2006, com o desenvolvimento das atividades do Seminário Integrador I que apresentou dois focos principais: (a) a alfabetização/inclusão tecnológica das professoras-alunas, considerando que grande parte delas nunca havia usado computadores e que a grande maioria sequer contava com endereço eletrônico e, (b) o planejamento do uso do tempo, considerando que as professoras-alunas tiveram que organizar e compatibilizar as atividades profissionais e familiares com as atividades de estudante.

A alfabetização/inclusão tecnológica ocorreu de forma articulada com as interdisciplinas do semestre. Partimos de uma atividade introdutória para todas as interdisciplinas que consistia em um trabalho sobre as "realidades" de cada professoraaluna, que foram registradas em ambientes virtuais (web 2.0).

Entre as tecnologias utilizadas, destacamos o ambiente ROODA (www.ead.ufrgs.br/rooda), uma das plataformas oficiais da UFRGS para educação a distância, onde se realizam preferencialmente as atividades de acompanhamento, comunicação, debates assíncronos, divulgação de materiais e propostas de atividades. O desenvolvimento de atividades cooperativas foi apoiado por ambientes de blog e wiki, além de sites para compartilhamentos de fotos e vídeos.

Após o período inicial de familiarização com as tecnologias tiveram início as atividades específicas das demais interdisciplinas do semestre.

Em 2007/1, o PEAD teve um novo ingresso de professoras-alunas que necessitaram realizar uma ambientação no curso e uma integração com o grupo que ingressou em 2006/2. Para facilitar a aproximação dos grupos (veteranos e "bixos”) e favorecer a alfabetização tecnológica das ingressantes, lançamos o projeto de extensão "Adote um Bixo”. No projeto, as professoras-alunas veteranas, por adesão, “adotaram” uma colega caloura para acompanhar e orientar quanto à organização inicial dos estudos e familiarização com as tecnologias digitais. As interações foram registradas em wikis, abertos pelos adotantes e facilitaram a interação entre os grupos, bem como a integração no curso.

O curso foi desenvolvido em nove eixos temáticos, organizados em interdisciplinas articuladas mediante uma temática norteadora. As propostas de trabalho eram avaliadas de forma conjunta pelas equipes das interdisciplinas ${ }^{4}$ do eixo visando buscar diálogos entre as áreas de conhecimento e adequações da carga horária semanal. Esse planejamento geral era flexibilizado conforme as especificidades dos polos e articulado sob a coordenação do Seminário Integrador. Essas articulações ocorriam considerando tanto as equipes de uma V. $11 \mathrm{~N}^{\circ}$ 2, novembro, 2013 PEAD 
$\Gamma$

mesma interdisciplina, quanto as equipes compostas pelas distintas interdisciplinas de um mesmo eixo em cada um dos polos. As equipes das interdisciplinas eram compostas por cinco docentes (um para cada polo) e por 2 ou 3 tutores em cada um dos polos.

\section{Acompanhamento e Recuperação}

O acompanhamento sistemático realizado pela equipe de tutoria mostrou-se fundamental para dar sustento ao desenvolvimento das interdisciplinas e evitar que as professoras-alunas se “distanciassem”, seja por dificuldades na vida pessoal, seja por dificuldades no atendimento às demandas do curso. Como forma de recuperação preventiva foi também definida, em cada semestre, uma "semana de atualização", dedicada exclusivamente ao desenvolvimento de atividades de recuperação e orientadas pelos docentes responsáveis pelas interdisciplinas. Um novo período de recuperação (duas semanas) ocorria ao final de cada semestre letivo.

Quando as professoras-alunas não alcançavam o aproveitamento para aprovação, havia ainda a possibilidade de nova matrícula em uma das interdisciplinas, a ser cursada em paralelo àquelas do eixo subsequente. Esta possibilidade se restringia a no máximo uma interdisciplina em cada eixo.

Considerando que PEAD ocorreu como um projeto especial de formação, não havia a possibilidade de trancamento de matrícula.

\section{Construção dos portfólios de avaliação}

A avaliação teve como foco o processo de construção das aprendizagens, segundo dois níveis complementares: a trajetória de aprendizagem das professoras-alunas no desenvolvimento das interdisciplinas e a avaliação integrada. Esse segundo nível foi organizado em três etapas: (1) desenvolvimento do portfólio de aprendizagens (memorial reflexivo), (2) elaboração da reflexão-síntese, com base no portfólio e, (3) apresentação oral da reflexão-síntese.

A partir do Eixo 2 cada professora-aluna desenvolveu o seu portfólio de aprendizagem, utilizando um suporte digital (blog), sendo acompanhada pelos tutores e professores do Seminário Integrador. A principal função do portfólio educacional na formação das professoras-alunas é criar um contexto favorável para a reflexão sobre as vivências e aprendizagens no curso e as possíveis reinterpretações e qualificações das suas práticas pedagógicas.

Este portfólio teve seu ponto culminante no Eixo 9 quando as professoras-alunas foram convidadas a revisitar os registros dos semestres anteriores e realizar uma ampla reflexão sobre as suas aprendizagens e sobre o entrelaçamentos das temáticas exploradas no decorrer do curso, buscando estabelecer uma relação entre as aprendizagens e as transformações em suas práticas pedagógicas.

\section{O Estágio Curricular e o Trabalho de Conclusão de Curso}

No Eixo 8 foi realizado o estágio curricular, caracterizado, segundo (Rela, Carvalho e Nevado, 2010), como um espaço de docência que privilegia um contínuo movimento de V. $11 \mathrm{~N}^{\circ}$ 2, novembro, 2013 PEAD 
$-\Gamma$

ação-reflexão-ação supervisionada durante o processo de formação, buscando a transformação/inovação nas práticas docente.

Cada estagiária recebeu duas visitas de supervisão na escola, incluindo-se as escolas rurais e de difícil acesso e dois encontros presenciais de orientação nos polos. Para dar suporte às atividades de acompanhamento e orientação online pelos docentes e tutores do curso foi utilizado um ambiente do tipo wiki, com acesso privado. Nesse ambiente virtual as estagiárias registraram os planejamentos, as atividades realizadas com alunos, acompanhadas de vídeos e fotos, além de reflexões sobre as atividades. Os comentários e orientações de tutores e orientadores foram realizados através de intervenções nos wikis, em chats e por email. Essa forma de orientação online favoreceu o acompanhamento e o feedback sistemático da equipe docente.

No nono eixo foi desenvolvido o Trabalho de Conclusão de Curso (TCC). Segundo o documento-guia (NEVADO, 2010), o TCC constituiu-se em um relato e análise de experiência, tendo como base as práticas realizadas nas escolas durante o estágio obrigatório. O TCC resultou da integração das construções teóricas e das experiências desenvolvidas ao longo do curso com as inovações pedagógicas realizadas durante o estágio curricular. A natureza formativa do TCC se constituiu como atividade de pesquisa, direcionada a identificar questões de investigação relevantes e suas possíveis soluções, no âmbito de um processo que considerou as especificidades do contexto em que cada estágio foi realizado. Cada TCC foi apresentado e avaliado por uma banca no workshop de avaliação final.

\section{Parte III - Algumas Conclusões}

As metas previstas foram cumpridas, com a realização dos nove semestres do Curso de Graduação em Pedagogia - Licenciatura na modalidade a distância com e a diplomação de 330 professoras-alunas.

Impactos sobre a vida das professoras-alunas: considerações sobre a avaliação do curso

Foram realizadas avaliações sistemáticas para identificação da satisfação dos alunos com o Curso durante o seu desenvolvimento e também para avaliar os impactos-do curso nas suas vidas, em âmbito profissional, pessoal e como alunos. ${ }^{5}$

Perguntou-se às professoras-alunas sobre o seu grau de satisfação com respeito às contribuições do curso para o desenvolvimento profissional, desenvolvimento pessoal e desenvolvimento como estudante. Os resultados estão expressos na tabela 1

\section{Tabela 1 - Grau de Satisfação com respeito às contribuições do Curso nas dimensões: Profissional, Pessoal e como Estudante (2009)}




\begin{tabular}{l} 
CINTED-UFRGS \\
\cline { 1 - 1 } \\
\hline
\end{tabular}

Como resultados das questões abertas nas quais as professoras-alunas listaram as contribuições do curso mais significativas para as suas vidas, destacamos:

(a) a incorporação e criação de novas práticas que se sustentam em maior embasamento teórico e postura reflexiva;

(b) a melhor organização do tempo para a conciliação de afazeres, principalmente o cuidado com os filhos e com a casa;

(c) a mudança na vida como estudante que desencadeou mais dedicação, vontade de conhecer, ler e buscar atualização;

(d) o uso das novas tecnologias nas escolas juntamente com a conquista de autoestima e sentimento de aumento da respeitabilidade junto à comunidade escolar;

(e) aumento da autonomia, iniciativa e posicionamentos frente às questões da Educação e da vida pessoal.

Ainda mediante questões abertas, solicitamos que elas apresentassem 3 características do curso consideradas por elas como positivas com respeito à facilitação das aprendizagens ${ }^{6}$. No total, 230 professoras-alunas responderam a questão, obtendo-se com isso 691 indicações.

As 26 características facilitadoras da aprendizagem destacadas foram agrupadas em quatro categorias. As indicações mostraram que as professoras-alunas consideraram como principais fatores facilitadores da aprendizagem resultantes do modelo de curso:

(i) a articulação dos componentes curriculares,

(ii) a aproximação teoria e prática,

(iii) o apoio qualificado de professores e tutores,

(iv) o estabelecimento de uma rede de interação, 
(v) o uso das tecnologias e a diversidade dos materiais digitais.

É importante salientar que as articulações entre os componentes curriculares (atividades integradas) e a aproximação entre teoria e prática, percebidas pelas professorasalunas como uma das principais características do PEAD foi viabilizada pela organização curricular, com destaque para o papel articulador desempenhado pelo Seminário Integrador e para a formação de uma rede de aprendizagem, apoiada pelas TDIC.

Essas indicações, aliadas às mudanças percebidas pelas professoras-alunas, mostram o alcance das metas do projeto pedagógico do PEAD, que visa qualificar os modos de fazer e pensar a escola. E ainda, ao atuar na promoção da reflexão, na organização do pensamento, na autonomia e na valorização de si o curso torna-se um fator de mudanças também na vida de estudante e na vida pessoal. 


\section{Considerações sobre os impactos do Curso}

Nas escolas: O PEAD já apresenta impactos significativos em escolas de Educação Infantil e de Anos Iniciais do Ensino Fundamental do Rio Grande do Sul, com a mudança nas práticas pedagógicas das professoras-alunas do Curso, ativação dos laboratórios de informática em decorrência da demanda dessas professoras-alunas e com a inserção de professoras-alunas na gestão dessas escolas. Conforme Trindade (2010) foi possível observar que a vivência do uso das TDIC e a introdução de novas metodologias favoreceram a experimentação de novas práticas nas escolas. O processo de transposição didática iniciou de forma natural, o que fortalece a hipótese de que a introdução de mudanças na escola é facilitada quando o professor vivencia essas mudanças na sua própria formação.

Na Universidade: O PEAD teve um impacto positivo dentro da Universidade Federal do Rio Grande do Sul (UFRGS), sendo o primeiro curso a distância, no âmbito da Universidade, a diplomar alunos e tendo a sua qualidade reconhecida pelos alunos, professores e tutores, bem como pela administração da UFRGS. Considerando os seus resultados positivos, no momento atual, a administração central da UFRGS e a direção da Faculdade de Educação estão articulando uma nova edição do curso que deverá ter início em 2014. Essa nova edição terá o seu desenvolvimento em três novos polos, definidos em função do levantamento das demandas de formação de professores no Rio Grande do Sul e também das regras atuais de utilização de polos do sistema $\mathrm{UAB}^{7}$. curso:

Destaca-se como aspectos favorecedores para a implantação de nova edição do

- a comprovação da viabilidade do modelo de curso interativo, mediado pelas TDIC, especialmente a internet;

- o contingente de docentes formadores e tutores formados em nível de especialização para o trabalho em EAD e com interesse em atuar em novas edições do PEAD;

- o acervo de conhecimento resultante de artigos científicos, trabalhos de conclusão de curso de especialização, dissertações e teses na linha de pesquisa Educação a Distância, entre outras linha do PPGEDU/UFRGS e CINTED/UFRGS, tendo o PEAD como objeto de estudo;

- a demanda ainda existente de professores da rede pública ainda sem habilitação em nível superior no estado do Rio Grande do Sul;

- núcleos de produção de materiais, laboratórios e polos de apoio presencial dentro da própria UFRGS.

\section{Considerações Finais}




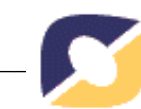

A realização dessa primeira edição do PEAD, considerando todos os desafios inerentes a implantação do primeiro curso de licenciatura a distância na Universidade, permitiu uma série de aprendizagens que reforçaram as convicções dos proponentes na possibilidade (que se realizou) de criação de novos modelos para a educação a distância. Dentre as muitas aprendizagens pode-se ainda destacar:

- a importância e necessidade da constituição, na universidade, do trabalho conjunto. A constituição das equipes das interdisciplinas (e, de forma especial a da equipe do Seminário Integrador) permitiu extrapolar fronteiras entre diferentes áreas do conhecimento, resultando em articulações que se concretizaram em atividades conjuntas e em uma forma de avaliação integrada em cada um dos eixos do curso;

- a valorização dos saberes e fazeres das professoras-alunas mostrou-se como condição relevante para o trabalho de articulação entre prática e teoria e também para que essas pudessem confiar no seu potencial para vencer os obstáculos próprios a faixa etária e condições de vida profissional e pessoal das professoras-alunas;

- é possível vencer a distância física e prevenir a evasão mediante outras formas de "presença", das quais destacamos a participação ativa e construtiva da rede de aprendizagem. A formação da rede mostrou-se fundamental para aproximar professoras-alunas, tutores e formadores mediante trocas intensivas;

- a presença dos docentes-formadores, que também interagiram diretamente com as professoras-alunas mostrou-se relevante na qualificação do trabalho;

- a opção por materiais digitais mostrou-se importante para promover a alfabetização e o letramento tecnológico, bem como uma cultura digital no curso e nas escolas das professoras-alunas;

- as formas de mediação, na direção do diálogo, da problematização e do apoio às construções são uma das condições mais importantes para promover a interação e a aprendizagem;

- é fundamental acompanhar e apoiar as equipes docentes que iniciam o trabalho a distância para que se estabeleça a mudança da "cultura presencial” para a "cultura do trabalho em EAD".

- Observou-se que é importante criar nos polos de apoio presencial uma série de atividades culturais/ educativas para além do currículo específico do curso que criem uma espécie de "ambiência universitária". Nessa primeira edição essa "ambiência” não pode ocorrer de forma intensiva já que os polos estavam em formação e ainda não apresentavam as condições necessárias para tal;

- é também essencial realizar pesquisas que acompanhem o desenvolvimento do curso para avaliar o modelo de curso e a prática do modelo e identificar os impactos do curso sobre os seus alunos.

No momento atual, além da preparação da nova edição do curso, prevista para 2014/1, planeja-se uma pesquisa acompanhando das professoras-alunas egressas, focando, V. $11 \mathrm{~N}^{\circ}$ 2, novembro, 2013 PEAD 


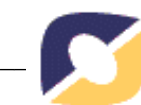

principalmente, na continuidade da formação e nas repercussões dessa formação nas escolas, seja na melhoria da gestão das escolas nas quais as professoras-alunas egressas atuam, seja na qualidade das práticas pedagógicas e aprendizagens dos seus alunos.

${ }^{1}$ Durante o ano de 2005 foram constituídas equipes de professores formadores para elaboração de material didático e reuniões de formação nas quais o projeto pedagógico do PEAD foi apresentado e discutido. Nesse período ocorreu, também, um curso de formação, em nível de aperfeiçoamento, para os tutores.

${ }^{2}$ A coordenação de polo constituiu-se uma função docente e foi exercida por professores vínculos a EAD/FACED/UFRGS, enquanto os gerentes de polo eram vinculados às prefeituras dos municípios-polo e tiveram como função administrar o polo, garantindo a sua infraestrutura e o seu funcionamento.

${ }^{3}$ A coordenação de polo constituiu-se uma função docente e foi exercida por professores vínculos a EAD/FACED/UFRGS, enquanto os gerentes de polo eram vinculados às prefeituras dos municípios-polo e tiveram como função administrar o polo, garantindo a sua infraestrutura e o seu funcionamento.

${ }^{4}$ Cada interdisciplina contou com um docente por polo e um coordenador de interdisciplina

${ }^{5}$ Essas avaliações estão sistematizadas no artigo "Inovações na Formação de Professores na Modalidade a Distância”, publicado na Revista ETD : Educação Temática Digital, v. 10, p. 373393, 2009

${ }^{6}$ Esse levantamento é detalhado no artigo "Pressupostos, intenções e práticas de um curso a distância: as contribuições das percepções dos alunos para a avaliação do modelo”, publicado na Revista Perspectiva, v. 30, n. 1, 2012.

7 Na primeira edição do PEAD, anterior a constituição do sistema UAB, os polos foram conveniados diretamente com as prefeituras dos municípios.

\section{Referências}

BORDAS, M. C., CARVALHO, M. J. S., e NEVADO, R. A. Formação de professores: pressupostos pedagógicos do Curso de Licenciatura em Pedagogia/EAD. Informática na Educação: Teoria e Prática. Porto Alegre. n 8(1), p. 143-167, 2005.

BORDAS, M.; NEVADO, R. A.; CARVALHO, M.J. S. (2004) Curso de Licenciatura em Pedagogia: Anos Iniciais do Ensino Fundamental- modalidade EAD. (projeto do curso)

BRASIL, Ministério da Educação, Instituto Nacional de Estudos e Pesquisas Anísio Teixeira. "Doc. Norteador, Grupo Tarefa da Licenciatura, SESU/MEC”, Disponível em http://www.inep.gov.br. Acesso em: 12 setembro 2013.

CARVALHO, M. J. S.; NEVADO, R. A.;e MENEZES, C. S. Arquiteturas Pedagógicas para Educação a Distância. In: NEVADO. R. A.; CARVALHO, M. J. S. e MENEZES, C. S. (Org.). Aprendizagem em Rede na Educação a Distância: Estudos e Recursos para Formação de Professores. Porto Alegre: Ricardo Lenz, 2007. 


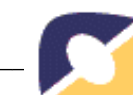

CHARCZUK, S. B. Interdisciplinaridade na Educação a Distância: estudo de caso no âmbito de um curso de pedagogia. PPGEDU/Universidade Federal do Rio Grande do Sul, 2012, 146p. Tese de doutorado. Disponível em: http://hdl.handle.net/10183/49083.

CONSELHO NACIONAL DE EDUCAÇÃO. Resolução CNE/CP No 1, de 15 de Maio de 2006.

COSTA, I. T; FAGUNDES, L. C; NEVADO, R. A. Projeto TecLec- Modelo de uma Nova Metodologia em EAD incorporando os Recursos da Telemática. In: Informática na Educação- Teoria e Prática. Porto Alegre, v.1 n.1. p.83-100, 2005.

NEVADO, R. A.; CARVALHO, M.J. S.;MENEZES,C.S. Inovações na formação de professores na modalidade a distância. ETD : Educação Temática Digital, v. 10, p. 373393, 2009.

NEVADO, R. A., CARVALHO, M. J. S; MENEZES, C. S. Educação a Distância mediada pela Internet: Uma abordagem Interdisciplinar na Formação de Professores em Serviço. RENOTE, v.4, n.2, p.1-11, 2006.

NEVADO, R. A.; CARVALHO, M. J. S.; BORDAS, M.C. Guia do Professor. Curso de Licenciatura em Pedagogia a Distância: Anos Iniciais do Ensino Fundamental, modalidade EAD. Faculdade de Educação/UFRGS. 2006.

NEVADO, R. MENEZES, C. Pressupostos, intenções e práticas de um curso a distância: as contribuições das percepções dos alunos para a avaliação do modelo”. Revista Perspectiva, UFSC, v. 30, n. 1, 2012.

SANTOS, Vanice dos. Ágora Digital: o cuidado de si no caminho do diálogo entre tutor e aluno em um ambiente virtual de aprendizagem. São Paulo: Paco Editorial, 2013.

TRINDADE, E.S.C. Contribuições da Formação de Professores para o uso das TICs na Escola: um estudo de caso no Curso de Graduação em Pedagogia- Licenciatura a Distância da Universidade Federal do Rio Grande do Sul. 2004. PPGEDU/Universidade Federal do Rio Grande do Sul, 133p. Dissertação de mestrado. Disponível em: http://hdl.handle.net/10183/26302.

ZIEDE, M. L. A Construção da Função dos Tutores no âmbito do Curso de Graduação em Pedagogia - Licenciatura na Modalidade a Distância da Faculdade de Educação da Universidade Federal do Rio Grande do Sul. 2008. PPGEDU/Universidade Federal do Rio Grande do Sul, 247p. Dissertação de mestrado. Disponível em: http://hdl.handle.net/10183/16186. 